\title{
Employee Not Meeting Expectations?
}

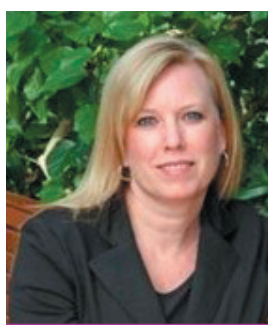

Trudi Charest, RO

Trudi Charest is the Co-founder of $4 E C P s$, a business resource company for eye care professionals. 4ECPs has six divisions marketing, training, social media, eye care jobsites, payments \& events. Trudi can be reached at trudi@4ecps.com or www.4ecps.com.

I $t$ can be surprising and frustrating when an employee is not living up to your expectations at work. Whether that is in their performance or attitude, something is not working and as the leader of the business you have to make some changes. Before you jump too quickly to letting them go or resorting to discipline, let's review the most common reasons someone is not meeting employer expectations:

\section{Not enough training}

We can't fault people for not doing what we expect if we never showed them how we wanted it done in the first place. So many workplaces leave the onboarding to one of the staff in the office with very little planning or preparation. The new employee gets hurried, ineffective training and then is expected to know it all. Set yourself up for success by developing a training program for all staff.

\section{Clear direction}

Similar to the first point, if you want something done in a particular fashion, then you need to clearly define what you want and how you want it completed. You will get far more out of all of your employees if you take the time to document all process, policies and procedures - including individual responsibilities - and sit down with each employee to review.

\section{They are disengaged}

If you have an employee who is actively disengaged in their role and daily tasks then how they perform them will be less than stellar. At this point you need to have a heart to heart with this employee and uncover the cause of their disengagement and whether there is the ability to turn it around. If not, actively manage them out of the business.

\section{Not the right fit}

You may have an employee in the wrong role. You might have them at reception when they really want to be in pre-test. It's not in their DNA to do the reception tasks and answer the phone all day but they are a great employee. Talk to the under-performing employee and see if it is a poor role fit or an understanding of the tasks at hand.

\section{Internal conflict}

We often see performance problems when there are underlying internal conflict issues as well. Maybe you have two team members who have had a disagreement and it has not been resolved. It may be affecting one or both of them to the degree that it is also affecting their daily work and responsibilities. Helping to get the issue resolved and the ability to move forward can immediately make a difference in their overall attitude.

\section{They don't get the big picture}

All employees need to understand what the mission of the practice is and what you believe in, so they are inspired and encouraged to work towards that objective every day with every patient. Let them know their purpose and role in achieving the mission so they feel invested and involved.

Last note: Most employees don't set out to under-perform. Most want the leaders to be happy with them and their work. By setting them up for success from the beginning with great leadership, clear direction and ongoing communication you may just see them living up to your expectations. 